\title{
Facilitating Work Engagement and Performance Through Strengths-Based Micro-coaching: A Controlled Trial Study
}

\author{
María Josefina Peláez ${ }^{1}$ (D) ${\text { Cristián } \text { Coo }^{1} \text { (D) } \cdot \text { Marisa Salanova }}^{1}$ (D)
}

(c) Springer Nature B.V. 2019

\begin{abstract}
In spite of the potential benefits that strengths-based coaching can bring to organizations, basic questions remain regarding its impact on work engagement and job performance specially among non-executive employees. In a controlled trial study, 60 employees from an automotive industry company participated in a strengths-based micro coaching program over a period of five weeks. The intervention followed a strengths-based coaching approach, grounded in the identification, development, and balanced use of personal strengths to foster positive outcomes. Mixed methods, using quantitative and qualitative measures, were taken. Both the participants and their supervisors completed pre, post, and follow-up questionnaires, and the results indicated that the intervention program was successful in increasing all the study variables after finishing the program. The results also showed the durability of the effects on the outcome variables over time (follow up). Qualitative data supported the study hypotheses. Through open questions inquiring about the outcomes of the program, the participants stated that it helped them to increase performance and well-being. Practical implications suggest that this program can be a valuable short-term applied positive psychology intervention to help employees increase their work engagement and performance and promote optimal functioning in organizations.
\end{abstract}

Keywords Strengths-based coaching $\cdot$ Work engagement $\cdot$ Performance $\cdot$ Control trial

\section{Introduction}

People possess unique signature strengths - such as courage, wisdom, and humor - that are linked to a sense of self, identity, and authenticity, and usually lead to a strong intrinsic motivation to put them into practice (Proctor et al. 2011). In organizational settings, the identification and use of personal strengths is a promising tool for increasing positive experiences, and promoting optimal functioning in the pursuit of goal achievement (Dubreuil et al. 2016; Linley 2008). Moreover, research suggests that strengths identification and application is a potentially important tool in personal and organizational development that

María Josefina Peláez

pelaezm@uji.es

1 Department of Psychology, WANT Research Team, Universitat Jaume I, Avenida Sos Baynat, s/n, 12071 Castellón de la Plana, Spain 
is becoming increasingly attractive to practitioners (Biswas-Diener et al. 2011). In a similar way, coaching psychology provides a remarkable opportunity to apply the principles of character strengths, based on positive psychology, to enhance well-being and achieve excellent performance in organizations (Grant and Cavanagh 2007). Specifically, strengthsbased coaching has been suggested as an applied link between strengths development and coaching psychology (Govindji and Linley 2007; Linley et al. 2010). Employees who use their strengths are more engaged at work (Harter et al. 2002) and more likely to achieve their goals (Biswas-Diener et al. 2011; Linley et al. 2010).

The highly competitive market that automotive companies face often requires an increasing complexity of the design processes and shorter delivery lead times. Manufacturing competitive priorities generally includes low cost, quality, time, flexibility and innovation (Bodein et al. 2013; Jayaram et al. 1999). In these contexts, employees highly involved in their work processes tend to increase their psychological work adjustment, well-being and effectiveness. Movement towards high involvement goals implies making better use of employees' capacities and personal development, if the company wishes to improve their productivity outcomes (Boxall and Macky 2009). Therefore, to enable employees achieve superior performance, coaching and support are necessary (Bodein et al. 2013).

In spite of the growing body of research about the effects of coaching, mainly executive coaching, on employees' well-being and performance in organizations (Grant 2013; Grant et al. 2009), little is known about the impact of coaching on these variables in nonexecutive employees (Grant 2013). Thus, there is still a need for empirical studies with strong designs to investigate possible effects of non-executive coaching on positive outcomes (Grant 2006; Green and Spence 2014) such as engagement and performance. Overall, given the increasing role of coaching in organizations worldwide (Grant 2013), further development of an evidence-based framework for strengths-based coaching is needed (Dubreuil et al. 2016; Biswas-Diener et al. 2011).

In order to address this research gap, the present study seeks to add to the literature by reporting on a controlled trial study that explored the impact of a non-executive Strengthsbased Micro-Coaching program on work engagement and job performance using mixed methods (quantitative and qualitative) in our research design. To measure job performance, both self-reported and supervisors' perceptions were considered. Finally, based on previous suggestions that coaching can be effective even when the number of coaching sessions is relatively small (Theeboom et al. 2014), we also aim to contribute to the positive psychology coaching literature by highlighting the usefulness of short-term coaching (i.e., microcoaching) as an applied positive psychology intervention that can be valuable in increasing engagement and optimal functioning in organizations.

\subsection{Strengths-Based Coaching as a Positive Psychological Intervention (PPI)}

Positive Psychology (PP) is defined as the scientific study of the optimal functioning of individuals and organizations (Seligman and Csikszentmihalyi 2014). The main objective of this discipline is to build positive qualities in order to facilitate happiness and subjective well-being. Based on the humanistic assumption that people are basically healthy and resourceful and want to lead meaningful and fulfilling lives, this discipline can be understood as a strengths-based psychology. Indeed, the strengths approach is one of the main pillars of PP.

A strength can be defined as a natural capacity for behaving, thinking, and feeling that is authentic and energizing to the individual and enables optimal functioning, development, 
and effectiveness (Linley and Harrington 2006). Seligman (2002) proposed 24 distinct character strengths ranging from creativity to leadership to humor and classified under the six virtues of wisdom, courage, love, justice, temperance, and spirituality. This taxonomy of strengths is known as the 'VIA' (Values In Action; see Peterson and Seligman 2004 for a review) inventory of strengths, which defines psychological or character strengths as morally valued traits whose use contributes to fulfillment and happiness. Linley and Harrington (2006) argued that when individuals use their signature strengths, they feel good about themselves, are better able to do what they naturally do best, and work toward fulfilling their potential. Currently, an increasing number of professionals (i.e. therapists, coaches, and consultants) are using strengths-based interventions with their clients because they have been found to be significantly associated with well-being (Park et al. 2004), happiness (Seligman et al. 2005), and goal attainment (Linley et al. 2010).

Recently, a newly applied sub-discipline of psychology has emerged, namely Coaching Psychology, which can be understood as a collaborative, solution focused, systematic methodology designed to enhance well-being, facilitate goal attainment, and foster purposeful, positive change (Grant et al. 2010). Within the framework of a collaborative relationship, a coach encourages the coachee to set and strive for personally meaningful goals by: (1) identifying desired outcomes, (2) establishing specific goals, (3) enhancing motivation by identifying personal strengths, (4) identifying resources and formulating action plans, (5) monitoring and evaluating progress, and (6) modifying action plans based on this evaluation (Grant 2011, 2013). In the field of business, the use of coaching as an important tool has increased substantially in the past two decades because it aims to optimize employees' work-related performance and achieve organizational success (Joo 2005). In this specific work context, coaching is increasingly being used not only as a means of enhancing employees' optimal functioning, but also as a tool for optimizing psychosocial well-being, especially from the perspective of positive psychology coaching.

There is a growing consensus among coaching psychology researchers that PP and coaching psychology are complementary partners because they share a focus on building on individuals' strengths in order to enhance health, growth, and development (BiswasDiener 2010; Biswas-Diener and Dean 2007). From this point of view strengths-based coaching is an example of the integration between both perspectives (Govindji and Linley 2007; Linley and Harrington 2006; Linley et al. 2010). This strengths-based approach aims to help clients identify their strengths and better direct their talents and abilities toward meaningful and engaging behaviors (Peterson and Seligman 2004).

Furthermore, previous research has demonstrated that emphasizing personal strengths in the workplace makes employees achieve their goals more effectively (Linley 2008), be more engaged (Harter et al. 2002), and perform better (Dubreuil et al. 2014). For these reasons, strengths-based coaching has been proposed as an effective organizational intervention for personal and organizational development (Biswas-Diener et al. 2011; Linley et al. 2009). One useful way to make personal strengths work to promote beneficial outcomes is by using them to achieve goals. Previous research suggests that it is not only goal attainment in itself that leads to well-being and better performance, but also the types of goals pursued and the motivation for pursuing them. In essence, people who seek goals that are consistent with their personal interests and values dedicate more continued effort to achieving these goals, and therefore are more likely to attain them (Govindji and Linley 2007; Linley et al. 2010).

Overall, the strengths-based approach offers a coherent theoretical framework and methodological consistency to the delivery of coaching in organizations (Mackie 2014). However, in spite of the potential benefits that strengths-based coaching can bring to 
organizations (Linley et al. 2009), only a few studies have proposed and tested strengthsbased interventions in work settings (Cable et al. 2013, 2015; Dubreuil et al. 2016; Harzer and Ruch 2016; Hodges and Asplund 2010; Lee et al. 2016; Meyers and van Woerkom 2017; Page and Vella-Brodrick 2010). Thus, further development of an evidence-based framework and empirical research on this approach are needed, especially with non-executive employees.

\subsection{Strengths-Based Coaching, Work Engagement, and Job Performance}

\subsubsection{Strengths-Based Coaching and Work Engagement}

Although coaching has primarily focused on the enhancement of optimal functioning, peak performance, and the achievement of organizational goals, more recently the emergence of Positive Psychology coaching methods that encourage employees to develop strengths, positive resources and achieve personally meaningful goals in organizational settings has led to coaching focusing on employees' well-being and engagement (Green and Spence 2014; McQuaid et al. 2018). Thus, work engagement is an important positive organizational outcome that can be promoted through strength coaching interventions (Crabb 2011).

Conceived as the opposite of job burnout, work engagement can be understood as a positive state of mind characterized by three dimensions: (1) vigor: which refers to high levels of energy and mental resilience, the willingness to invest effort in one's work, and persistence in facing difficulties; (2) dedication: which refers to strong involvement, that is, psychological identification with one's work, and characterized by a sense of significance, enthusiasm, pride, inspiration, and challenges; and (3) absorption: which refers to a state of complete concentration and being engrossed in one's activities (Schaufeli et al. 2002). As previous researchers have noted (Llorens-Gumbau and Salanova-Soria 2014; Salanova et al. 2016), work engagement arises from a motivational process that begins with the availability of job resources that stimulate employees' motivation, and therefore leads to desirable work outcomes, such as life satisfaction, autonomy, positive affect, efficacy beliefs, organizational commitment and higher job performance. Hence, this positive state of mind is an important indicator of occupational well-being for both employees and organizations (Bakker and Demerouti 2017; Knight et al. 2017).

Grant and Cavanagh (2007) suggested workplace engagement as an important outcome to include in research examining the effect of coaching interventions. Other researchers have highlighted the predictive role of core aspects of coaching (e.g. generating meaningful and positive feedback, clarity of goals) in enhancing work engagement (Bakker et al. 2008). However, to date, few attempts have been made to develop frameworks for organizational coaching that integrate and explore the impact on this dependent variable (Grant et al. 2010). In one of the few randomized controlled trials conducted to date, Duijts et al. (2008) found some evidence that coaching significantly reduced participants' levels of burnout and improved general health, life satisfaction, and psychological well-being (Green and Spence 2014). In a diary study, Xanthopoulou et al. (2009) reported that coaching had a direct positive relationship with work engagement. To explain this relationship, the authors proposed that individuals working in a resourceful work environment, such as one where they receive high-quality coaching, are likely to believe more in their own capabilities, feel valued, and be optimistic that they will meet their goals. Consequently, employees 
experience goal self-concordance, which may lead to higher levels of work engagement (Hobfoll 2002).

Furthermore, previous research has demonstrated that playing up one's personal strengths makes employees more engaged at work (Harter et al. 2002; Dubreuil et al. 2016). Related to the first dimension of engagement (vigor), and according to Linley's model (2008), when people use their strengths, they feel that they have more positive energy available to them and are more alive and vigorous. This intensified feeling of energy would be partly responsible for optimal functioning and performance, allowing people to work more vigorously and for longer periods of time. Another central feature of strengths use related to engagement (i.e. absorption and dedication) is that individuals "often" experience a state of deep concentration and involvement in an activity while using their strengths (Dubreuil et al. 2014). Despite the well-known benefits of using strengths at work and the growing popularity of strengths-based coaching in organizations (Dubreuil et al. 2014; Linley et al. 2009), the impact of this intervention on employees' work engagement has hardly been assessed.

Hypothesis 1 Participants will increase their levels of work engagement after the intervention (from Pre to Post), and compared to a Waiting List-control group (WL).

\subsubsection{Strengths-Based Coaching and Job Performance}

Another way coaching can benefit organizational effectiveness is through its potential impact on employees' performance (Grant 2013). The definition of Job Performance generally includes two dimensions: (1) in-role or task performance, which includes activities related to the formal job that directly serve the goals of the organization, and (2) extra-role or contextual performance, which denotes actions that exceed what the employee is supposed to do (e.g., helping others or voluntary overtime; Goodman and Svyantek 1999). This second dimension of performance refers to citizenship behaviors that directly promote the effective functioning of an organization without necessarily directly influencing an employee's productivity (Podsakoff et al. 2000).

Previous meta-analytic studies have confirmed the strong relationship between coaching and job performance. Coaching in organizations is essentially a relatively straightforward process of setting goals and developing action plans with the ultimate objective of optimizing employees' work-related functioning and performance (Grant 2013; Theeboom et al. 2014). Coaching can foster performance by helping employees to establish self-concordant goals, increase their motivation, and become involved in cognitive preparations such as self-awareness and the potential for growth and development (Grant 2011, 2013). The use of simple process models such as the Review, Evaluation, Goal, Reality, Options, Wrap-up model (RE-GROW; see Grant 2003, 2011; Whitmore 1992 for review) encourages coaches to take ownership of their goal striving and behavior change. This coaching process creates a self-regulation cycle that is important for successful behavior change and, thus, better performance.

Although coaching has been widely used in workplaces for several decades, there is still relatively little research on its impact and effectiveness (Green and Spence 2014). Particularly in the relationship with job performance, the few randomized controlled studies carried out to date indicate that coaching can indeed improve goal attainment (Grant et al. 2009) and performance (Kines et al. 2010). However, these studies were conducted with executives or employees through workplace coaching by their managers as coaches (Grant 
2013). To the authors' knowledge, to date, no controlled studies of coaching conducted with non-executives by professional external coaches have assessed coaching's impact on job performance (in-role and extra-role). Although the training of managers in coaching skills represents a significant contribution to rise coaching in the workplace, one of the main benefits of appealing to external coaching providers is the need in organizations to distinguish formal coaching from the intermittent use of coaching skills by line managers in their supervisory duties. Additionally, external coaches' specific knowledge domain and expertise (e.g. therapeutic approaches, psychological models, organization development), professional practice and external perspective to the organization are also identified as key factors in coaching success. (Grant et al. 2010).

Moreover, previous research has found the use of strengths to be positively associated with work performance. In essence, individuals who have opportunities to apply their strengths at work are more likely to demonstrate work performance behaviors, not only by fulfilling their required tasks, but also by adapting better to change and acting more proactively in their work environments (Dubreuil et al. 2014; Hodges and Asplund 2010). Thus, the use of strengths would be associated with both in-role and extra-role performance.

Further research has proposed three underlying psychological processes that might be operating in the relationship between strength use and job performance. When people use their strengths, they: (1) feel like they have more energy available to them; (2) experience a feeling of authenticity, described as a feeling of being true to oneself and following one's own direction, thus, making employees feel genuine and like they are in the right role at work; and (3) experience a state of deep concentration and involvement in an activity, thus engaging in greater cognitive activity and attaining self-concordant goals and success at work (Dubreuil et al. 2014; Linley 2008). Therefore, work engagement, with its three dimensions (vigor, dedication and absorption), can be understood as an underlying psychological mechanism that explains how the use of strengths is related to job performance.

Despite the growing popularity and well-known benefits of strength-based coaching in organizations, so far very little is known about the impact of this intervention on employees' performance (Dubreuil et al. 2014; Hodges and Asplund 2010). This is surprising, considering that one of the main goals of the strengths-based approach is to foster optimal functioning (Linley et al. 2010). Furthermore, another important aspect in assessing the efficacy of coaching is collecting ratings not only from the coachees themselves (selfreported), but also from supervisors' perceptions of the outcome variables (Grant 2013). Therefore, we formulate the following hypotheses:

Hypothesis 2 Participants will increase both their self-reported and supervisor reported levels of job performance after the intervention (from Pre to Post), and compared to WL.

\subsubsection{The Durability of the Effects}

Previous research suggests that longitudinal research is needed in order to ensure that the impact of coaching is more than just the result of engagement in a helping relationship. Therefore, it is essential to develop and conduct rigorous follow-up studies to establish the effectiveness of a coaching intervention over time (Grant and Cavanagh 2007). The few longitudinal studies conducted to date have indicated that coaching produces sustained changes (Grant and Cavanagh 2007; Grant 2013). For instance, in a randomized control study, Green et al. (2006) found that gains from participation in a 10-week, solution-focused, cognitive-behavioral life coaching program were maintained at the 30 -week 
follow up. In another longitudinal study, Libri and Kemp (2006) conducted an 18-month follow-up study, and the results indicated that coaching enhanced employees' sales performance and core self-assessments.

Furthermore, previous research has highlighted the important role of the use of strengths as a predictor of well-being over time. Wood et al. (2011) confirmed that people who use their strengths experience greater vitality and positive affect over a long period of time. Moreover, preliminary results from longitudinal research with health sector workers indicated that, following a strengths-development intervention, strength use led to increases in positive outcomes (i.e. subjective vitality and concentration), which in turn led to increases in work performance and satisfaction (Forest et al. 2013). However, there is a gap in the research due to the lack of longitudinal studies that assess the impact of strengths-based coaching on employees' positive outcomes in organizations (Govindji and Linley 2007). Therefore, in the current study, we attempt to investigate the durability of the effects on the outcome variables (work engagement and job performance) four months after finishing the intervention program.

Hypothesis 3 The whole intervention group (EX plus WL) will maintain their increases in work engagement and job performance four months after the intervention program (Follow up; FUP), compared to Pre intervention.

\section{Method}

\subsection{Participants and Procedure}

The present study was conducted in a multinational automotive industry company located in Spain. The researchers contacted the manager of the plant with whom they arranged an initial meeting in order to evaluate the possibility of implementing a positive psychology intervention in the company. During the meeting, the plant manager expressed the employees' need to develop personal resources and motivation in order to address the high demands (e.g., high levels of workload, time pressure, responsibility, shift work) they face in their daily work and achieve ambitious performance goals.

Seventy-six employees who held technical or engineering positions with non-supervisory or executive responsibilities were invited to participate in a Strengths-based MicroCoaching program through two informational meetings. During these meetings, participants were informed about the nature and characteristics of the study, the aims of the intervention program, and the evaluation procedure. Additionally, they were told that the confidentiality of their replies would be guaranteed according to the European data regulation standards. Participation was entirely voluntary, and there were no additional economic rewards or employee benefits for their involvement in the study. The study adhered to ethical standards, and was part of a broader research project called "Success factors, best practices and positive interventions in healthy and resilient organizations", which was approved by the Research Ethics Committee of Universitat Jaume I, in Spain.

A total of 60 employees (79\%) initially agreed to participate. Next, participants were distributed into: (1) the experimental condition ( $\mathrm{EX} ; \mathrm{N}=35$ ), divided into six groups that took part simultaneously, and (2) the waiting-list control condition (WL; N=25), which served as an untreated comparison during the study. The groups were not randomly chosen because many of the participants worked with rotating schedules in the manufacturing 


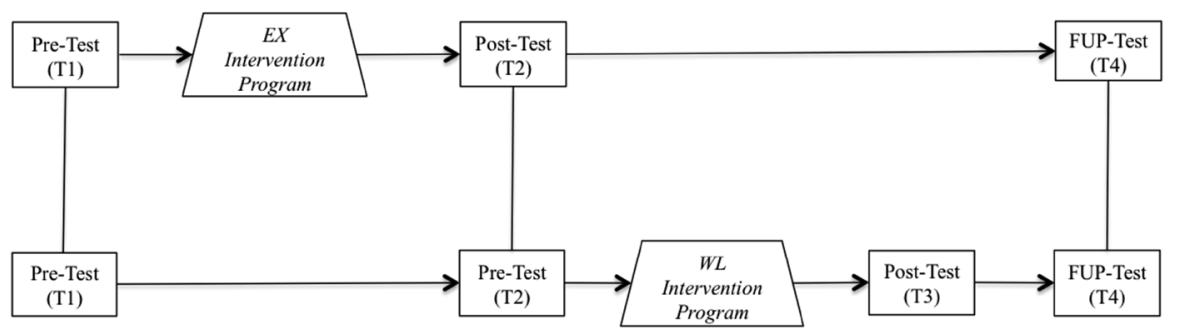

Fig. 1 Experimental design of the study. T1-time 1; T2-time 2; T3-time 3; T4-time 4; EX-experimental group; WL-waiting list-control group

plant, and therefore the company preferred them to choose between both groups depending on the workshops dates and their work shifts. After the EX finished the program, the three remaining groups that made up the WL also participated in the intervention program.

The empirical research was carried out using a mixed methodology, both quantitative and qualitative. With regards to the quantitative method, online questionnaires were distributed via direct links sent by email to each participant $(\mathrm{N}=60)$ at different times: before starting the program (T1; Pre intervention self-assessment), after finishing the program the EX (T2; Post intervention self-assessment for EX and Pre intervention self-assessment for WL), after finishing the program the WL (T3; Post intervention self-assessment just for WL), and four months after finishing the program each group (T4; FUP intervention selfassessment). Participants were asked to complete the surveys during working hours, and the approximate time it took to answer them was $15 \mathrm{~min}$. At the beginning of the questionnaire, participants signed an informed consent form agreeing to release their personal data for scientific research exclusively. Supervisors' $(\mathrm{N}=9)$ ratings as measures of employee's Job Performance were included in order to obtain an external performance assessment and avoid common method variance. Each supervisor evaluated between 3 and 16 employees $(\mathrm{M}=5.7 ; \mathrm{SD}=2.2)$.

The company supported the study by allowing employees to attend sessions during work hours. Due to unexpected changes in work demands, organizational restructuring, or personal reasons, four employees did not complete the intervention program. Therefore, 56 (93\%) participants finished the program and completed the Post questionnaires, whereas 52 (87\%) responded to the FUP questionnaire. For organizational reasons, the WL groups started the intervention immediately after the EX groups finished (after T2 evaluation), rather than waiting until the completion of the FUP questionnaires. Figure 1 outlines the research design of the study. Last but not least, qualitative data was gathered through open questions obtained from the last individual coaching sessions.

The average age for the participants was 36 years ( $\mathrm{SD}=7.5$, ranging from 22 to 52$)$, and $70 \%$ were male. Moreover, $82 \%$ had a tenured contract, and the average job tenure in the company was 8.57 years $(\mathrm{SD}=8.5)$.

\subsection{Strengths-Based Coaching Program Description}

The intervention developed in this study was called the "Strength-based Micro-Coaching Program", and it was conducted by professional coaching psychologists external to the organization. The aims of the program were: (1) to present and deliver feedback on the self-assessment results related to the participants' positive psychological resources 


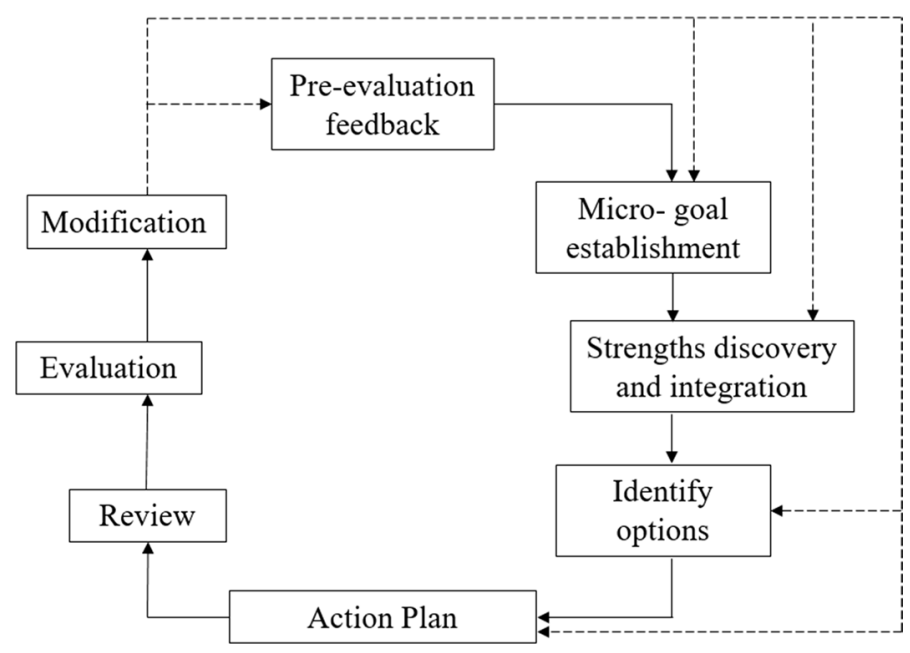

Fig. 2 Intervention program model based on the generic self-regulation cycle (Grant 2003)

(self-efficacy, resilience, hope and optimism), Work Engagement and Job Performance, (2) to support participants' goal achievement through the development of an action plan based on personal strengths, and (3) to increase participants' Work Engagement and Job Performance.

The intervention followed a strengths-based approach (Linley et al. 2010), and the REGROW (Grant 2003, 2011) model was used to structure the program. Based on these two approaches, the intervention focused on the establishment of a specific goal related to personal and professional development, followed by an action plan based on the identification, development, and use of personal strengths. The steps followed during the entire program were based on the generic self-regulation cycle (see Grant for review, 2003) which consists of a series of processes that includes setting a goal, developing an action plan, monitoring and evaluating the progress through self-reflection and changing actions to further enhance performance and achieve goals. The intervention model of the present study (see Fig. 2) expands Grant's model by including a self-assessment feedback as a first step previous to establishing the goal, and strengths discovery and integration step followed by identifying options step before developing the action plan.

The intervention program lasted for a period of six weeks and was delivered in a twohour group workshop session, followed by three individual coaching sessions. Previous research confirmed that the number of coaching sessions is not related to the effectiveness of the intervention, and, thus, even short-term coaching can be effective (Theeboom et al. 2014).

First, during the group workshop session, participants received Positive Psychology and Coaching Positive Psychology academic input. Next, feedback on the self-assessment results was given, with the objective of making them aware of their self-perceived personal resources, engagement and performance variables. Supervisors' scores reports were not included in the feedback delivered by the external coaches in this group session. The company considers that it is the supervisor's task to deliver performance feedback to each employee as a regular procedure due to the international policy of the company. So far, that was not part of the intervention program. 
Based on these results, participants established a specific goal related to their personal and professional development. In addition, a booklet was provided containing work slogans, information relevant to each coaching session, instructions for coaching activities, and suggested reading materials. Participants also gave written qualitative feedback on their experiences in the workshop and their key learning points.

After the workshop, the participants went through two weekly 90-minute individual sessions, which consisted of the (re) definition of the established goal and the development of an action plan for goal achievement, based on personal strengths. This strengths-based approach was based on previous work (e.g. Biswas-Diener 2010; Dubreuil et al. 2016; Linley 2008; Seligman et al. 2005) and involved three steps: (1) discovery: participants were invited to identify their strengths based on the VIA, and through symbol identification and answering powerful questions; (2) integration: participants were invited to reflect on and analyze their strengths, areas of improvement, and external opportunities for goal achievement; and (3) action: during the development of the action plan, participants were invited to think about ways they could use their strengths at work to better achieve their goals. Additionally, between sessions, participants did specific exercises related to the development of the action plan at work.

Finally, two weeks after finishing the two 90-min sessions, participants received a follow-up 60-min final session with the aim of supervising the action plan, savoring the positive outcomes and goal attainment, and receiving feedback on the program, in order to ensure the transfer of training back into their day-to-day work. During this session, the "Best Possible Self" exercise (BPS; Peters et al. 2010), followed by visualization techniques, was practiced as a closing activity. Participants were invited to write, based on their strengths, about a better future where they imagined themselves in the best possible condition in relation to the achievement of the goal, considering three specific areas (personal, professional, and social). These authors found BPS manipulation to be effective in increasing psychological well-being and personal resources.

\subsection{Measures}

\subsubsection{Work Engagement}

Work Engagement was measured by a nine-item short version of the Utrecht Work Engagement Scale (Schaufeli et al. 2006). The scale includes three dimensions measured by three items each: (1) vigor $(\alpha=0.92)$, (i.e., "At my work, I feel bursting with energy"), (2) dedication $(\alpha=0.84)$, (i.e., "I am enthusiastic about my job"), and (3) absorption ( $\alpha=0.81)$, (i.e., "I am immersed in my work"). All the items were rated on a seven-point Likert scale ranging from 0 (almost never) to 6 (almost always).

\subsubsection{Job Performance}

Job Performance was assessed by six items included in the HERO (HEalthy \& Resilient Organization) questionnaire (Salanova et al. 2012) and adapted from the Goodman and Svyantek scale (1999). Participants were asked to rate each of the statements individually using a seven-point Likert scale ranging from 0 (strongly disagree/never) to 6 (strongly agree/always). Two dimensions were considered, with three items in each: (1) in-role performance $(\alpha=0.75)$, (i.e., "I achieve the objectives of the job") and (2) extra-role performance $(\alpha=0.83)$, (i.e., "I help other employees with their work when they have been 
absent"). The same measure was administrated to supervisors, but on these questionnaires, supervisors were asked to think about their employees' Job Performance.

\subsubsection{Qualitative Measure}

Participants were asked to respond to an open-question (i.e. "What specific positive outcomes (if any) did you gain from participating in this program?") to obtain information about the outcomes and benefits of the intervention program.

\subsection{Data Analyses}

First, descriptive analyses and inter-correlations among the study variables were performed. Then, one-factor Analyses of Variance (ANOVA) were applied, using SPSS, to examine whether there were significant differences between the EX and WL conditions in the demographic variables before the intervention took place. Next, to test the effects of the intervention program, data were analyzed with a $2 \times 2$ repeated-measures ANOVA consisting of one between-subjects factor (group: EX, WL) and one within-subjects factor (time: T1, T2). Additionally, paired-sample $t$ tests were implemented to test for differences between Pre (T1)- and Post (T2)-time factors for EX, and Pre (T2)- and Post (T3) times for WL. The FUP (T4) time factor was not calculated for the WL group because they had completed the intervention before the third evaluation was administrated.

Furthermore, univariate analyses for all outcome variables were also applied to identify effects possibly overlooked in the analysis of variance. Interaction effects were examined by comparing time factors (T1, T2) across each group (EX, WL). A significance level of 0.05 was established for all tests. Following Cohen (1988), Cohen's d as a measure of effect sizes in paired-sample $t$ tests for both EX and WL results and $t$ test comparisons between groups, and eta squared in the repeated measures ANOVA were also estimated.

Moreover, once the WL had completed the intervention program, paired-sample $t$ tests were implemented for the whole intervention group (EX plus WL) to test for differences between Pre $(\mathrm{N}=60)$, Post $(\mathrm{N}=56)$, and FUP $(\mathrm{N}=52)$. Both self-reported and supervisor scores were used. Cohen's d measures of effect sizes were also calculated for the whole intervention group.

Finally, participants' responses were systematically classified and grouped by thematic content, in order to analyze qualitative data on the outcomes of the intervention program (Ahuvia 2001; Denecke and Nejdl 2009). Next, frequency and percentage of each emerging category were estimated.

\section{Results}

\subsection{Self-Reported Measure Results}

Table 1 shows means, standard deviations, internal consistencies (Cronbach's $\alpha$ ), and correlations between the outcome variables for Pre, Post and FUP scores for the whole intervention group (EX plus WL, $\mathrm{N}=60$ ). Next, we tested whether there were significant differences between EX and WL on the demographic variables before the intervention (Pre-time). One-factor ANOVA results indicated no differences between the two groups on the socio-demographic data [age $(F(1,59)=0.34 ; p=0.56, n s ;)$, gender 
Table 1 Pre, Post, and FUP intervention means, standard deviations, internal consistencies, and correlations of all the variables for the whole intervention group

\begin{tabular}{|c|c|c|c|c|c|c|}
\hline Variables & M & SD & $\alpha$ & 1 & 2 & 3 \\
\hline \multicolumn{7}{|l|}{ Pre intervention scores } \\
\hline 1. Work Engagement & 4.75 & 0.81 & 0.92 & - & & \\
\hline 2. Job Performance (Self-reported) & 4.86 & 0.75 & 0.83 & $0.33 *$ & - & \\
\hline 3. Job Performance (Supervisors) & 4.60 & 0.98 & 0.92 & 0.09 & 0.12 & - \\
\hline \multicolumn{7}{|l|}{ Post intervention scores } \\
\hline 1. Work Engagement & 4.92 & 0.81 & 0.92 & - & & \\
\hline 2. Job Performance (Self-reported) & 5.24 & 0.72 & 0.92 & $0.50 * *$ & - & \\
\hline 3. Job Performance (Supervisors) & 4.89 & 0.83 & 0.93 & 0.23 & $0.42 * *$ & - \\
\hline \multicolumn{7}{|l|}{ FUP intervention scores } \\
\hline 1. Work Engagement & 4.83 & 0.87 & 0.95 & - & & \\
\hline 2. Job Performance (Self-reported) & 5.16 & 0.77 & 0.93 & $0.42 * *$ & - & \\
\hline 3. Job Performance (Supervisors) & 4.77 & 0.86 & 0.90 & 0.07 & 0.05 & - \\
\hline
\end{tabular}

Correlations; $* * p<0.01 ; * p<0.05$
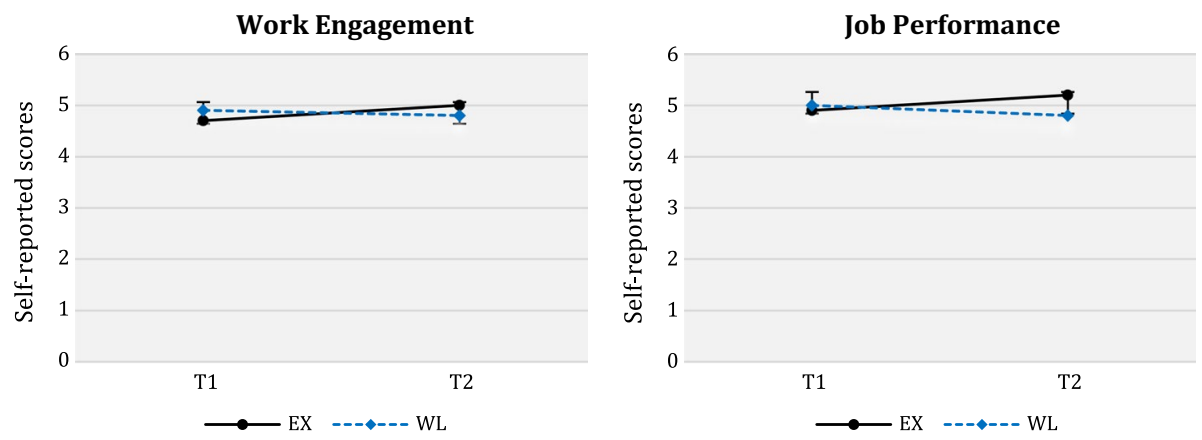

Fig. 3 Self-reported plotted means for each time factor (T1, T2) across groups

$(F(1,59)=2.04 ; p=0.16, n s ;)$ and years of tenure $(F(1,58)=01.68 ; p=0.56, n s ;)]$. With these results, we proceeded to carry out the study, concluding that the two groups were comparable.

A repeated-measures ANOVA showed a significant time (T1, T2) x group (EX, WL) interaction effect for the outcomes variables [Work Engagement $(F(1,55)=5.95$, $\left.p<0.05, \eta_{\mathrm{p}}^{2}=0.020\right)$, and Job Performance $\left.\left(F(1,55)=9.02, p<0.005, \eta_{\mathrm{p}}^{2}=0.059\right)\right]$. These results indicated that EX had significantly higher scores than WL at Post intervention (T2) compared to Pre (T1). The differences demonstrated a small effect size for Work Engagement, and an intermediate effect size for self-reported Job Performance. Figure 3 shows plotted means for each time factor (T1, T2) across the groups (EX, WL) for each outcome variable.

Paired-sample $t$ test results for EX indicated significant differences in all the dependent variables' mean scores between evaluation times [Work Engagement $(t(35)=-2.80$; $p<0.01, d=0.95)$, and Job Performance $(t(35)=-2.45 ; p<0.05, d=0.83)]$, with higher scores at $\mathrm{T} 2$ compared to $\mathrm{T} 1$. The differences demonstrated large effect sizes for 
both variables. However, for WL, paired-sample $t$ test results indicated no significant differences from T1 to T2 [Work Engagement $(t(20)=0.88 ; n s)$ and Job Performance $(t(20)=1.83 ; n s)]$.

Furthermore, results of $t$ test comparisons between groups (EX, WL) showed no significant differences in the outcome variables at T1 [Work Engagement $(t(58)=-0.07 ; n s)$ and Job Performance $(t(58)=0.07 ; n s)]$. In addition, results at T2 indicated that there were no significant differences between groups for Work Engagement $[t(54)=1.04 ; n s]$ and Job Performance $[t(54)=1.68 ; n s]$.

Finally, paired-sample $t$ test results for the whole intervention group (EX plus WL, $\mathrm{N}=54$ ) indicated significantly higher scores on all the dependent variables at Post compared to Pre intervention times [Work Engagement $(t(54)=-2.38 p<0.05, d=0.65)$ and Job Performance $(t(54)=-3.69 p<0.001, d=1.01)]$, revealing an intermediate effect size for Work Engagement and a large effect size for Job Performance. Moreover, results from Pre to FUP showed significant differences in Job Performance $[t(47)=-2.78 p<0.01$, $d=0.81$, indicating a large effect size, but not Work Engagement $[t(46)=-0.86 ; n s]$.

\subsection{Supervisor Measure Results}

A repeated-measures ANOVA for Job Performance showed a significant time (T1, T2) $\mathrm{x}$ group $(\mathrm{EX}, \mathrm{WL})$ interaction effect for supervisors' scores $[F(1,51)=10.28 ; p<0.005$, $\left.\eta_{\mathrm{p}}^{2}=0.078\right]$, indicating that supervisors evaluated EX participants with significantly higher scores than WL participants at T2 compared to T1. The difference demonstrated an intermediate effect size for this variable. Figure 4 shows plotted means for each time factor (T1, T2) across the groups (EX and WL).

Paired-sample $t$ test results for the EX group indicated significant differences in the scores given by supervisors for Job Performance between T1 and T2 $[t(33)=-4.72$; $p<0.001, d=1.64$ ], with higher scores at $\mathrm{T} 2$, indicating an intermediate effect size for this variable. As expected, for the WL group, paired-sample $t$ test results showed no significant differences from $\mathrm{T} 1$ to $\mathrm{T} 2[t(18)=0.77 ; n s]$.

Furthermore, results of $t$ test comparisons of supervisors' scores between groups (EX, WL) showed no significant differences in Job Performance at T1 $[t(51)=0.91 ; n s]$. However, results at T2 indicated significant differences between groups $[t(56)=2.18 ; p<0.05$, $d=0.58]$ on the same outcome variable, with higher scores for EX group. This difference revealed an intermediate effect size.

Fig. 4 Supervisors' plotted means for each time factor (T1, T2) across groups

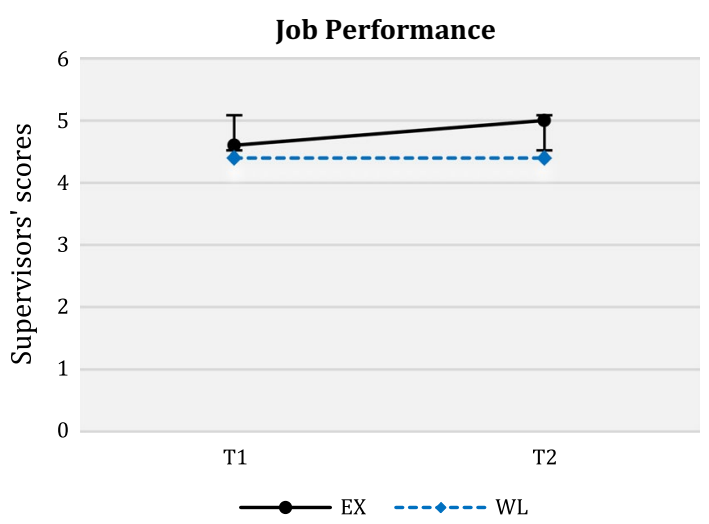



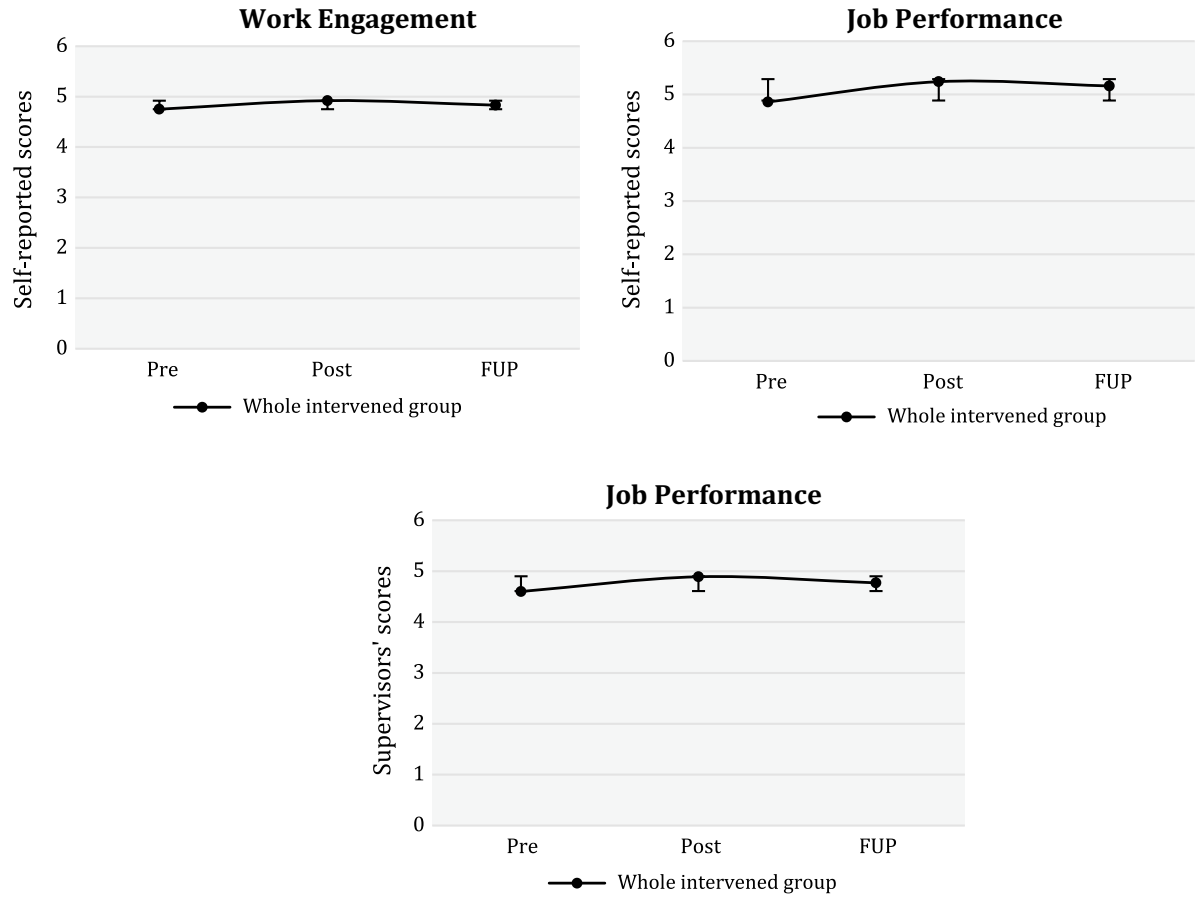

Fig. 5 Dependent variables for the whole intervention group across time

Table 2 T1-T2 means and standard deviations (SD) for EX and WL groups

\begin{tabular}{|c|c|c|c|c|c|c|c|c|}
\hline & \multicolumn{4}{|c|}{$\mathrm{EX}(\mathrm{N}=35)$} & \multicolumn{4}{|c|}{$\mathrm{WL}(\mathrm{N}=25)$} \\
\hline & $\mathrm{T} 1$ & $\mathrm{~T} 2$ & $t$ value & $p$ value & $\mathrm{T} 1$ & $\mathrm{~T} 2$ & $t$ value & $p$ value \\
\hline \multicolumn{9}{|l|}{ Self-reported scores } \\
\hline Work Engagement & $4.7(0.75)$ & $5.0(0.64)$ & -2.80 & 0.008 & $4.9(0.70)$ & $4.8(0.93)$ & 0.88 & 0.386 \\
\hline Job Performance & $4.9(0.65)$ & $5.2(0.75)$ & -2.45 & 0.017 & $5.0(0.61)$ & $4.8(0.91)$ & 1.83 & 0.083 \\
\hline \multicolumn{9}{|l|}{ Supervisors' scores } \\
\hline Job Performance & $4.6(0.98)$ & $5.0(0.87)$ & -4.72 & 0.000 & $4.4(0.97)$ & $4.4(0.79)$ & 0.77 & 0.643 \\
\hline
\end{tabular}

Finally, paired-sample $t$ test results for the whole intervention group $(\mathrm{N}=60)$, after WL had completed the program, indicated significantly higher supervisor scores for Job Performance at Post $(M=4.86)$ compared to Pre intervention time $[M=4.60$; $(\mathrm{t}(52)=-4.90 p<0.000, d=1.36)]$, indicating a large effect size. However, the results showed no significant differences from Pre to FUP $(\mathrm{M}=4.77)[t(52)=-1.27 ; n s]$. Figure 5 shows plotted means for the whole intervention group for self-reported and supervisors' scores.

Means and standard deviations for self-reported and supervisors' scores for each variable across both groups at different times (T1 and T2) are shown in Table 2. 


\subsection{Qualitative Data}

Participants $(\mathrm{N}=56)$ responses to the qualitative question ("What specific outcomes did you gain from participating in this program?") obtained from the last individual coaching session were classified, and are presented below, listed by order of frequency with which they were mentioned by the participants: (1) 37 responses $(42 \%)$ were related to 'goal attainment and increased job performance' (e.g., "Improvements in the definition of goals and the ability to achieve them"); (2) 34 responses (38.6\%) were related to 'awareness and development of strengths and personal resources' (e.g., "Awareness of how I am, of my strengths and areas of improvement"); and (3) 17 (19.3\%) were related to 'increased satisfaction and well-being' (e.g., "Satisfaction of having achieved the goal").

\section{Discussion}

The purpose of this study was to evaluate the impact of participating in a non-executive Strengths-based Micro-Coaching Program on employees' Work Engagement and Job Performance. Overall, the results of the study are consistent with the proposed hypothesis. After participating in the program, participants showed significant increases in both outcome variables. Therefore, findings from this study contribute to the coaching psychology literature by highlighting that short-term strengths coaching can be a valuable applied positive psychology intervention to increase well-being and optimal functioning in organizations. Thus, the results from the study are consistent with previous research suggesting that coaching can be effective even when the number of coaching sessions is relatively small (Theeboom et al. 2014) and, in this specific case, when signature strengths are used as the main tool during the coaching sessions. In addition, the results extend the literature on empirical randomized control trial studies with longitudinal designs considering the perceptions of both employees and their supervisors.

Specifically, regarding the impact of the intervention program on Work Engagement, the results supported $\mathrm{H} 1$, indicating that after participating in the program (Post-time), participants perceived significant increases in their levels of Work Engagement, when comparing EX and WL and when considering the whole intervention group. These findings are congruent with previous research confirming the positive and direct effect of coaching (Grant and Hartley 2014; Xanthopoulou et al. 2009) and the use of personal strengths at work (Harter et al. 2002; Dubreuil et al. 2016) on work engagement. Additionally, the qualitative results indicated that participants found that the program helped them to increase satisfaction and wellbeing. Based on the assumption that work engagement can be considered a positive, work-related state of wellbeing (Schaufeli et al. 2002), this qualitative finding contributed to confirming $\mathrm{H} 1$ of the present study.

Furthermore, considering the effects of the program on Job Performance, the results fully supported H2; that is, participants' levels of Job Performance (both self-reported and perceived by their supervisors) significantly increased after participating in the program (Post time), both compared to WL (from T1 to T2) and considering the whole intervention group (from Pre to Post times). Additionally, qualitative data also confirmed $\mathrm{H} 2$, showing that the most relevant outcome of participating in the program was an increase in goal attainment and job performance. 
The results are consistent with previous meta-analytic studies showing the impact of coaching on job performance in a variety of empirical studies (Grant 2013; Theeboom et al. 2014). Specifically, the few randomized controlled studies carried out to date have confirmed the positive effect of executive coaching on goal attainment (Grant et al. 2009) and the impact of employee workplace coaching on performance (Kines et al. 2010). Furthermore, the results also contribute to the strengths-based coaching literature, highlighting the strong association between the use of strengths and performance (Dubreuil et al. 2014; Hodges and Asplund 2010).

Moreover, although results on the durability of the effects indicated that all the outcome variables' levels remained higher at FUP compared to Pre-intervention in the whole intervention group, the difference was only statistically significant in self-reported levels of Job Performance, indicating that employees who participated in the program perceived their levels of performance significantly higher from Pre to FUP. This result is consistent with previous longitudinal studies showing that coaching (Libri and Kemp 2006) and strengthsbased interventions (Forest et al. 2013) enhance employees' performance over time. Additionally, even though participants' levels of Work Engagement and supervisors' perception of Job Performance were also higher four months after finishing the program, compared to baseline levels, the differences were not statistically significant, and the levels at FUP started to decrease somewhat over time. Thus, H3 was only partially confirmed. We believe that one of the reasons for this could be the lack of a second follow-up session one or two months after finishing coaching in order to monitor progress and ensure that participants stay motivated and persist in their goal achievement.

Finally, the participants' qualitative responses not only supported the quantitative findings about the expected outcomes of the program, but they also revealed that the Strengthsbased Coaching intervention was successful in helping participants to gain awareness and develop strengths and personal resources. This finding is consistent with previous research indicating that: (1) coaching has a positive impact on psychological characteristics (e.g. self-efficacy, resilience, hope; Franklin and Doran 2009), and (2) strengths-based coaching helps individuals to build on their strengths and personal resources (Biswas-Diener and Dean 2007; Govindji and Linley 2007; Proctor et al. 2011).

\subsection{Limitations and Future Research}

The present study also has some limitations. First, a strictly randomized assignment of the participants to the experimental conditions was not possible. However, one-factor ANOVA results revealed no significant differences between EX and WL groups on the socio-demographic data, and results from $t$ test comparisons between both groups also showed no significant differences in the outcome variables at $\mathrm{T} 1$ (before starting the intervention).

Second, because this study reports on data collected in one specific organization within the automotive sector, the findings cannot be generalized to other organizations or settings. Therefore, future research should implement and explore the impact of this intervention program in companies of other sectors to further compare the results.

A third limitation is that because a field study was conducted in a real organization, the research design had to be adapted to the organizational context. For instance, the WL groups started the intervention immediately after the EX groups finished, and, thus, comparisons of the two conditions at FUP could not be estimated. However, considering the whole intervention group (EX and WL), paired-sample $t$ test comparisons across the three evaluation times (Pre, Post and FUP) were calculated and showed interesting results. 
Moreover, considering that the levels of the outcome variables showed a decreasing pattern at FUP, although the levels remained higher than at Pre intervention, future studies should include follow-up coaching sessions over time in order to maintain and optimize the outcome variables.

Finally, to the authors' knowledge, this study is the first to explore the impact of a nonexecutive, short-term, strengths-based coaching program on work engagement and job performance using a randomized control design. Although we found positive effects that confirmed our hypotheses, further research is needed to better understand the underlying psychological mechanisms throughout the intervention program that can influence the outcome variables. For instance, diary study evaluation and data from each coaching session could offer relevant information about the evaluation process. Furthermore, upcoming studies could also evaluate the impact of this intervention program on the development and use of personal strengths and resources, in addition to objective organizational performance metrics. Finally, employees' appraisals of the intervention process (e.g. employees' readiness for change and involvement, exposure to components of the intended intervention, line managers' actions, etc.) should also be considered because previous research suggests that they can explain variance in the outcomes and, thus, determine the success of an intervention (Randall et al. 2009).

Acknowledgements The authors would like to thank Eduardo Guillamón (Manufacturing Engineering Manager at Ford Valencia Engine Plant), Pascual Chanzá Canut (Employee Suggestions Program Coordinator at Ford Valencia Engine Plant) and WANT Research Team members, for their useful cooperation during the implementation of the intervention program. Funding was provided by Universitat Jaume I (Grant No. \#B/2017/81) and Spanish Ministry of Economy and Competitiveness (Grant No. \#PSI2015-64933-R).

\section{References}

Ahuvia, A. (2001). Traditional, interpretive, and reception based content analyses: Improving the ability of content analysis to address issues of pragmatic and theoretical concern. Social Indicators Research, 54(2), 139-172.

Bakker, A. B., \& Demerouti, E. (2017). Job demands-resources theory: Taking stock and looking forward. Journal of Occupational Health Psychology, 22(3), 273. https://doi.org/10.1037/ocp0000056.

Bakker, A. B., Schaufeli, W. B., Leiter, M. P., \& Taris, T. W. (2008). Work engagement: An emerging concept in occupational health psychology. Work \& Stress, 22(3), 187-200. https://doi.org/10.1080/02678 370802393649.

Biswas-Diener, R. (2010). Practicing positive psychology coaching: Assessment, activities, and strategies for success. Hoboken, NJ: Wiley. https://doi.org/10.1002/9781118269633.

Biswas-Diener, R., \& Dean, B. (2007). Positive psychology coaching: Putting the science of happiness to work for your clients. New York: Wiley. https://doi.org/10.1080/17439760902992498.

Biswas-Diener, R., Kashdan, T. B., \& Minhas, G. (2011). A dynamic approach to psychological strength development and intervention. The Journal of Positive Psychology, 6(2), 106-118. https://doi. org/10.1080/17439760.2010.545429.

Bodein, Y., Rose, B., \& Caillaud, E. (2013). A roadmap for parametric CAD efficiency in the automotive industry. Computer-Aided Design, 45(10), 1198-1214. https://doi.org/10.1016/j.cad.2013.05.006.

Boxall, P., \& Macky, K. (2009). Research and theory on high-performance work systems: Progressing the high-involvement stream. Human Resource Management Journal, 19(1), 3-23. https://doi.org/10.111 1/j.1748-8583.2008.00082.x.

Cable, D. M., Gino, F., \& Staats, B. R. (2013). Breaking them in or eliciting their best? Reframing socialization around newcomers' authentic self-expression. Administrative Science Quarterly, 58(1), 1-36. https://doi.org/10.1177/0001839213477098.

Cable, D., Lee, J. J., Gino, F., \& Staats, B. R. (2015). How best-self activation influences emotions, physiology and employment relationships. Harvard Business School NOM Unit working paper (16-029).

Cohen, J. (1988). Statistical power analysis for the behavioral sciences (2nd ed.). Hillsdale: Laurence Erlbaum Associates. https://doi.org/10.2307/2290095. 
Crabb, S. (2011). The use of coaching principles to foster employee engagement. The Coaching Psychologist, 7(1), 27-34.

Denecke, K., \& Nejdl, W. (2009). How valuable is medical social media data? Content analysis of the medical web. Information Sciences, 179(12), 1870-1880. https://doi.org/10.1016/j.ins.2009.01.025.

Dubreuil, P., Forest, J., \& Courcy, F. (2014). From strengths use to work performance: The role of harmonious passion, subjective vitality, and concentration. The Journal of Positive Psychology, 9(4), 335-349. https://doi.org/10.1080/17439760.2014.898318.

Dubreuil, P., Forest, J., Gillet, N., Fernet, C., Thibault-Landry, A., Crevier-Braud, L., et al. (2016). Facilitating well-being and performance through the development of strengths at work: Results from an intervention program. International Journal of Applied Positive Psychology, 1(1-3), 1-19. https://doi. org/10.1007/s41042-016-0001-8.

Duijts, S. F., Kant, I., van den Brandt, P. A., \& Swaen, G. M. (2008). Effectiveness of a preventive coaching intervention for employees at risk for sickness absence due to psychosocial health complaints: Results of a randomized controlled trial. Journal of Occupational and Environmental Medicine, 50(7), 765776. https://doi.org/10.1097/jom.0b013e3181651584.

Forest, J., Dubreuil, P., Thibault-Landry, A., Girouard, S., \& Crevier, L. (2013). Increasing work performance through strengths use: Demonstration of the efficiency of an intervention. Manuscript in preparation.

Franklin, J., \& Doran, J. (2009). Does all coaching enhance objective performance independently evaluated by blind assessors? The importance of the coaching model and content. International Coaching Psychology Review, 4(2), 128-144.

Goodman, S. A., \& Svyantek, D. J. (1999). Person-organization fit and contextual performance: Do shared values matter. Journal of Vocational Behavior, 55(2), 254-275. https://doi.org/10.1006/ jvbe.1998.1682.

Govindji, R., \& Linley, P. A. (2007). Strengths use, self-concordance and well-being: Implications for strengths coaching and coaching psychologists. International Coaching Psychology Review, 2(2), $143-153$.

Grant, A. M. (2003). The impact of life coaching on goal attainment, metacognition and mental health. Social Behavior and Personality: An International Journal, 31(3), 253-263. https://doi.org/10.2224/ sbp.2003.31.3.253.

Grant, A. M. (2006). Workplace and executive coaching: A bibliography from the scholarly business literature. In A. M. Grant \& D. R. Stober (Eds.), Evidence based coaching (pp. 367-388). Hoboken, NJ: Wiley.

Grant, A. M. (2011). Is it time to REGROW the GROW model? Issues related to teaching coaching session structures. The Coaching Psychologist, 7(2), 118-126.

Grant, A. M. (2013). The efficacy of coaching. In Handbook of the psychology of coaching and mentoring (pp. 15-39). https://doi.org/10.1002/9781118326459.ch2.

Grant, A. M., \& Cavanagh, M. J. (2007). Evidence-based coaching: Flourishing or languishing? Australian Psychologist, 42(4), 239-254. https://doi.org/10.1080/00050060701648175.

Grant, A. M., Curtayne, L., \& Burton, G. (2009). Executive coaching enhances goal attainment, resilience and workplace well-being: A randomised controlled study. The Journal of Positive Psychology, 4(5), 396-407. https://doi.org/10.1080/17439760902992456.

Grant, A. M., \& Hartley, M. (2014). Exploring the impact of participation in a Leader as Coach programme using the Personal Case Study Approach. The Coaching Psychologist, 10(2), 51-58.

Grant, A. M., Passmore, J., Cavanagh, M. J., \& Parker, H. M. (2010). 4 The state of play in coaching today: A comprehensive review of the field. International Review of Industrial and Organizational Psychology, 25(1), 125-167. https://doi.org/10.1002/9780470661628.ch4.

Green, L. S., Oades, L. G., \& Grant, A. M. (2006). Cognitive-behavioral, solution-focused life coaching: Enhancing goal striving, well-being, and hope. The Journal of Positive Psychology, 1(3), 142-149. https://doi.org/10.1080/17439760600619849.

Green, S., \& Spence, G. B. (2014). Evidence-based coaching as a positive psychological intervention. In The Wiley Blackwell handbook of positive psychological interventions (pp. 273-285). https://doi. org/10.1002/9781118315927.ch15.

Harter, J. K., Schmidt, F. L., \& Hayes, T. L. (2002). Business-unit-level relationship between employee satisfaction, employee engagement, and business outcomes: A meta-analysis. Journal of Applied Psychology, 87(2), 268-279. https://doi.org/10.1037//0021-9010.87.2.268.

Harzer, C., \& Ruch, W. (2016). Your strengths are calling: Preliminary results of a web-based strengths intervention to increase calling. Journal of Happiness Studies, 17(6), 2237-2256. https://doi. org/10.1007/s10902-015-9692-y. 
Hobfoll, S. E. (2002). Social and psychological resources and adaptation. Review of General Psychology, 6(4), 307-324. https://doi.org/10.1037//1089-2680.6.4.307.

Hodges, T. D., \& Asplund, J. (2010). Strengths development in the workplace. In P. Linley, S. Harrington, \& N. Garcea (Eds.), Oxford handbook of positive psychology and work (pp. 213-220). New York, NY: Oxford University Press. https://doi.org/10.1093/oxfordhb/9780195335446.001.0001.

Jayaram, J., Droge, C., \& Vickery, S. K. (1999). The impact of human resource management practices on manufacturing performance. Journal of Operations Management, 18(1), 1-20. https://doi. org/10.1016/s0272-6963(99)00013-3.

Joo, B. K. (2005). Executive coaching: A conceptual framework from an integrative review of practice and research. Human Resource Development Review, 4(4), 462-488. https://doi.org/10.1177/15344 84305280866.

Kines, P., Andersen, L. P., Spangenberg, S., Mikkelsen, K. L., Dyreborg, J., \& Zohar, D. (2010). Improving construction site safety through leader-based verbal safety communication. Journal of Safety Research, 41(5), 399-406.

Knight, C., Patterson, M., \& Dawson, J. (2017). Building work engagement: A systematic review and meta-analysis investigating the effectiveness of work engagement interventions. Journal of Organizational Behavior, 38(6), 792-812.

Lee, J. J., Gino, F., Cable, D. M., \& Staats, B. R. (2016). Preparing the self for team entry: How relational affirmation improves team performance. Harvard Business School NOM Unit working paper (16-111).

Libri, V., \& Kemp, T. (2006). Assessing the efficacy of a cognitive behavioural executive coaching programme. International Coaching Psychology Review, 1(2), 9-20.

Linley, P. A. (2008). Average to a+: Realising strengths in yourself and others. Coventry: CAPP Press.

Linley, P. A., \& Harrington, S. (2006). Strengths coaching: A potential-guided approach to coaching psychology. International Coaching Psychology Review, 1(1), 37-46.

Linley, P. A., Nielsen, K. M., Gillett, R., \& Biswas-Diener, R. (2010). Using signature strengths in pursuit of goals: Effects on goal progress, need satisfaction, and well-being, and implications for coaching psychologists. International Coaching Psychology Review, 5(1), 6-15.

Linley, P. A., Woolston, L., \& Biswas-Diener, R. (2009). Strengths coaching with leaders. International Coaching Psychology Review, 4(1), 37-48.

Llorens-Gumbau, S., \& Salanova-Soria, M. (2014). Loss and gain cycles? A longitudinal study about burnout, engagement and self-efficacy. Burnout Research, 1(1), 3-11. https://doi.org/10.1016/j. burn.2014.02.001.

MacKie, D. (2014). The effectiveness of strength-based executive coaching in enhancing full range leadership development: A controlled study. Consulting Psychology Journal: Practice and Research, 66(2), 118-137. https://doi.org/10.1037/cpb0000005.

McQuaid, M., Niemiec, R., \& Doman, F. (2018). A character strengths-based approach to positive psychology coaching. In S. Green \& S. Palmer (Eds.), Positive psychology coaching in practice (pp. 71-79). New York: Routledge. https://doi.org/10.4324/9781315716169-5.

Meyers, M. C., \& van Woerkom, M. (2017). Effects of a strengths intervention on general and workrelated well-being: The mediating role of positive affect. Journal of Happiness Studies, 18(3), 671689. https://doi.org/10.1007/s10902-016-9745-x.

Page, K., \& Vella-Brodrick, D. (2010, February). Working for wellness: Practical and creative methods for enhancing employee well-being. In 2nd Australian positive psychology and well-being conference, Melbourne (Vol. 1213).

Park, N., Peterson, C., \& Seligman, M. E. (2004). Strengths of character and well-being. Journal of Social and Clinical Psychology, 23(5), 603-619. https://doi.org/10.1521/jscp.23.5.603.50748.

Peters, L. M., Flink, I. K., Boersma, K., \& Linton, S. J. (2010). Manipulating optimism: Can imagining a best possible self be used to increase positive future expectancies? The Journal of Positive Psychology, 5(3), 204-211. https://doi.org/10.1080/17439761003790963.

Peterson, C., \& Seligman, M. E. (2004). Character strengths and virtues: A handbook and classification (Vol. 1). New York: Oxford University Press. https://doi.org/10.5860/choice.42-0624.

Podsakoff, P. M., MacKenzie, S. B., Paine, J. B., \& Bachrach, D. G. (2000). Organizational citizenship behaviors: A critical review of the theoretical and empirical literature and suggestions for future research. Journal of Management, 26(3), 513-563. https://doi.org/10.1177/014920630002600307.

Proctor, C., Maltby, J., \& Linley, P. A. (2011). Strengths use as a predictor of well-being and healthrelated quality of life. Journal of Happiness Studies, 12(1), 153-169. https://doi.org/10.1007/s1090 2-009-9181-2. 
Randall, R., Nielsen, K., \& Tvedt, S. D. (2009). The development of five scales to measure employees' appraisals of organizational-level stress management interventions. Work \& Stress, 23(1), 1-23. https:// doi.org/10.1080/02678370902815277.

Salanova, M., Llorens, S., Cifre, E., \& Martínez, I. M. (2012). We need a hero! Toward a validation of the healthy and resilient organization (HERO) model. Group and Organization Management, 37(6), 785-822. https://doi.org/10.1177/1059601112470405.

Salanova, M., Llorens, S., \& Martínez, I. M. (2016). Aportaciones desde la psicología organizacional positiva para desarrollar organizaciones saludables y resilientes [Contributions from positive organizational psychology to develop healthy and resilient organizations]. Papeles del Psicólogo, 37(3), 177-184.

Schaufeli, W. B., Bakker, A. B., \& Salanova, M. (2006). The measurement of work engagement with a short questionnaire: A cross-national study. Educational and Psychological Measurement, 66(4), 701-716. https://doi.org/10.1177/0013164405282471.

Schaufeli, W. B., Salanova, M., González-Romá, V., \& Bakker, A. B. (2002). The measurement of engagement and burnout: A two sample confirmatory factor analytic approach. Journal of Happiness studies, 3(1), 71-92. https://doi.org/10.1037/t07164-000.

Seligman, M. (2002). Authentic happiness: Using the new positive psychology to realize your potential for lasting fulfilment. New York, NY: The Free Press.

Seligman, M. E., \& Csikszentmihalyi, M. (2014). Positive psychology: An introduction. In Flow and the foundations of positive psychology (pp. 279-298). Springer Netherlands. https://doi. org/10.1007/978-94-017-9088-8_18.

Seligman, M. P., Steen, T. A., Park, N., \& Peterson, C. (2005). Positive psychology progress: Empirical validation of interventions. The American Psychologist, 60(5), 410-421. https://doi. org/10.1037/0003-066x.60.5.410.

Theeboom, T., Beersma, B., \& Van Vianen, A. E. (2014). Does coaching work? A meta-analysis on the effects of coaching on individual level outcomes in an organizational context. The Journal of Positive Psychology, 9(1), 1-18. https://doi.org/10.1080/17439760.2013.837499.

Whitmore, J. (1992). Coaching for performance. London: Nicholas Brealey.

Wood, A. M., Linley, P. A., Maltby, J., Kashdan, T. B., \& Hurling, R. (2011). Using personal and psychological strengths leads to increases in well-being over time: A longitudinal study and the development of the strengths use questionnaire. Personality and Individual Differences, 50(1), 15-19. https://doi. org/10.1016/j.paid.2010.08.004.

Xanthopoulou, D., Bakker, A. B., Demerouti, E., \& Schaufeli, W. B. (2009). Work engagement and financial returns: A diary study on the role of job and personal resources. Journal of Occupational and Organizational Psychology, 82(1), 183-200. https://doi.org/10.1348/096317908x285633.

Publisher's Note Springer Nature remains neutral with regard to jurisdictional claims in published maps and institutional affiliations. 